\title{
Increasing Polyaromatic Hydrocarbon (PAH) Molecular Coverage during Fossil Oil Analysis by Combining Gas Chromatography and Atmospheric-Pressure Laser Ionization Fourier Transform Ion Cyclotron Resonance Mass Spectrometry (FT-ICR MS)
}

\author{
Paolo Benigni $^{\dagger}$, J. Daniel DeBord ${ }^{\dagger}$, Christopher J. Thompson $^{\ddagger}$, Piero Gardinali ${ }^{\perp, \dagger}$, and \\ Francisco Fernandez-Lima ${ }^{*}, \dagger, \S$ \\ tDepartment of Chemistry and Biochemistry, Florida International University, Miami, Florida \\ 33199, United States
}

‡Bruker Daltonics, Inc., Billerica, Massachusetts 01821, United States

${ }^{\perp}$ Southeast Environmental Research Center (SERC), Florida International University, Miami, Florida 33199, United States

§Biomolecular Sciences Institute, Florida International University, Miami, Florida 33199, United States

\begin{abstract}
Thousands of chemically distinct compounds are encountered in fossil oil samples that require rapid screening and accurate identification. In the present paper, we show for the first time, the advantages of gas chromatography (GC) separation in combination with atmospheric-pressure laser ionization (APLI) and ultrahigh-resolution Fourier transform ion cyclotron resonance mass spectrometry (FT-ICR MS) for the screening of polyaromatic hydrocarbons (PAHs) in fossil oils. In particular, reference standards of organics in shale oil, petroleum crude oil, and heavy sweet crude oil were characterized by GC-APLI-FT-ICR MS and APLI-FT-ICR MS. Results showed that, while APLI increases the ionization efficiency of PAHs, when compared to other ionization sources, the complexity of the fossil oils reduces the probability of ionizing lower-concentration compounds during direct infusion. When gas chromatography precedes APLI-FT-ICR MS, an increase (more than 2-fold) in the ionization efficiency and an increase in the signal-to-noise ratio of lower-concentration fractions are observed, giving better molecular coverage in the $\mathrm{m} / z 100$ 450 range. That is, the use of GC prior to APLI-FT-ICR MS resulted in higher molecular coverage, higher sensitivity, and the ability to separate and characterize molecular isomers, while maintaining the ultrahigh resolution and mass accuracy of the FT-ICR MS separation.
\end{abstract}

*Corresponding Author Tel.: 305-348-2037. Fax: 305-348-3772. fernandf@ fiu.edu..

Supporting Information The Supporting Information is available free of charge on the ACS Publications website at DOI: 10.1021/ acs.energy-fuels. 5 b02292.

Additional information as noted in the text (Figures S-1, S-2, and S-3, and Table S-1) (PDF)

The authors declare no competing financial interest. 


\section{INTRODUCTION}

While fossil oil bulk features can be resolved using infrared and near-infrared spectroscopy, molecular component characterization is traditionally limited to mass spectrometry (MS) based techniques (more details are given in refs 1 and 2). Over the last decades, multiple MS-hyphenated techniques have been successfully applied to the characterization of fossil oils (e.g., gas chromatography-mass spectrometry (GC-MS), ${ }^{3,4}$ two-dimensional gas chromatography-mass spectrometry (2D GC-MS), ${ }^{5}$ liquid chromatography-mass spectrometry (LC-MS), ${ }^{6,7}$ and, more recently, ion mobility spectrometry-mass spectrometry $(\text { IMS-MS })^{8-13}$ ). In particular, the advantages of Fourier transform ion cyclotron resonance mass spectroscopy (FT-ICR MS) analyzers for the identification of a large number of chemical components during a single analysis of fossil oils using high mass accuracy and ultrahigh mass resolution has been previously described. ${ }^{14-18}$

With the development of atmospheric-pressure ionization (API) sources, multiple studies have shown unique advantages for the characterization of fossil oils targeting different functional groups, aromatic content, and polarity (e.g., electrospray ionization (ESI), ${ }^{19}$ atmospheric-pressure photo ionization (APPI), ${ }^{20,21}$ atmospheric-pressure chemical ionization (APCI), ${ }^{22-24}$ atmospheric-pressure laser ionization (APLI), ${ }^{25-28}$ laser desorption ionization (LDI), ${ }^{29-31}$ direct analysis in real time (DART), ${ }^{32,33}$ desorption electrospray ionization (DESI), ${ }^{34}$ laser-induced acoustic desorption electron impact (LIAD-EI), ${ }^{35}$ laserinduced acoustic desorption chemical ionization (LIAD-CI), ${ }^{36}$ and low-temperature plasma $(\mathrm{LTP})^{37}$ ). While prior studies have described the coupling of chromatographic separations with electron impact sources (e.g., GC-EI-TOF-MS, ${ }^{38}$ GC-EI-QLT-Orbitrap, ${ }^{39}$ and GC-EIFT-ICR MS ${ }^{40,41}$ ), more recently, the GC and LC coupling to API-FT-ICR MS has shown advantages for the detection of molecular components and the separation of isomeric components (e.g., GC-APCI-FT-ICR MS, ${ }^{15,42}$ and HPLC-ESI/APCI/APPI/APLI-FT-ICR $\left.\mathrm{MS}^{43,44}\right)$.

The work described herein focuses on the analysis of PAHs from fossil oils using APLI and ultrahigh-resolution FT-ICR MS spectrometry (APLI-FT-ICR MS). Previous studies have shown that, compared to APCI and APPI, APLI is more suitable for the characterization of conjugated PAHs with increased sensitivity and selective ionization of highly conjugated compounds using lower-resolution MS analyzers. ${ }^{27,45-47}$ Results will show, for the first time, the advantages of combining GC separation and APLI-FT-ICR MS for the screening of PAHs in fossil oils (GC-APLI-FT-ICR MS). The screening potential of GC-APLI-FT-ICR MS is illustrated with the analysis of three reference fossil oil standards: organics in shale oil (OSO), petroleum crude oil (PCO), and heavy sweet crude oil (HSO). It will be shown that the use of retention time and accurate mass measurements for unambiguous identification of molecular components and structural assignments in complex mixtures has potential for targeted analysis and fingerprinting of lower-concentration fractions in the low mass range in fossil fuels. 


\section{EXPERIMENTAL SECTION}

\section{Sample Preparation}

Standard reference materials of organics in shale oil (OSO, SRM 1580), petroleum crude oil (PCO, SRM 1582), and heavy sweet crude oil (HSO, SRM 2722) were obtained from the National Institute of Standards and Technology (Baltimore, MA) and used as received. More-detailed information on the PAHs and alkyl-PAHs content for SRM 1580/1582 and on the sulfur content $(0.21 \% \mathrm{wt} / \mathrm{wt})$ for SRM 2722 can be found in the certificates. ${ }^{48-50}$ Prior analysis, samples were diluted at 1:5, 1:10, and 1:100 (v/v) ratios for direct-infusion APLI and 1:100 (v/v) for GC-APLI in Optima-grade hexane (Fisher Scientific, Waltham, MA).

\section{APLI-FT-ICR MS Analysis}

Individual standards were directly infused into a custom-built atmospheric-pressure laser ionization source (APLI) source using a vaporizer at a constant temperature of $300{ }^{\circ} \mathrm{C}$ at a rate of $200 \mu \mathrm{L} / \mathrm{h}$. (See details of the APLI source and coupling in Figure S-1 in the Supporting Information.) Details on the APLI principles of operation can be found elsewhere. ${ }^{27}$ Briefly, a $266 \mathrm{~nm}$ laser beam (CryLas GmbH, Berlin, Germany; Type 1HP266-50) is introduced orthogonal to the glass capillary source inlet of the 7T Solarix FTICR MS spectrometer (Bruker Daltonics, Inc., Billerica, MA). A molecular beam intercepts the laser beam and molecules are ionized via a two-photon (1+1) ionization mechanism and introduced into a FT-ICR MS spectrometer. ${ }^{51}$ Samples were analyzed in positive-ion mode and ion transmission was optimized for the $m / z$ 100-900 range. Ions were accumulated in the collision cell ( $2 \mathrm{MHz}, 1000 \mathrm{Vpp}$ ) for $0.1 \mathrm{~s}$ during detection using "Accumulate During Detect" mode in order to reduce overall analysis time. FT-ICR MS spectra were acquired over 25 time domain acquisition at 4 MWord ( $2 \mathrm{~s}$ transient). FT-ICR signals were processed using a half-sine apodization followed by fast-Fourier transform and broadband phase correction (absorption spectra using absorption mode processing (AMP)), ${ }^{52,53}$ resulting in an $\sim$-fold increase in mass resolution (experimental MS resolving power with AMP at $m / z$ 400 of 424000 ).

\section{GC-APLI-FT-ICR MS Analysis}

Individual standards were separated using a custom-built gas chromatography (GC) and introduced to the APLI source via a GC transfer line heated to $300{ }^{\circ} \mathrm{C}$ (more details on the GC-APLI coupling in Figure S-1). This source is now commercially available via Bruker Daltonics, Inc. GC separation was performed using a DB-5 Ms+DG column (30 m $\times 0.25$ $\mathrm{mm}, 0.25 \mu \mathrm{m}$ thickness, from Agilent Technologies, Inc., Palo Alto, CA). The GC injection chamber was held at $200{ }^{\circ} \mathrm{C}$ and $1 \mu \mathrm{L}$ of sample was introduced at a 1:20 split ratio. The GC method consisted of a $110-230{ }^{\circ} \mathrm{C}$ ramp at a rate of $10{ }^{\circ} \mathrm{C} / \mathrm{min}$, followed by a $230-310{ }^{\circ} \mathrm{C}$ ramp at a rate of $5{ }^{\circ} \mathrm{C} / \mathrm{min}$, and held for $7 \mathrm{~min}$ for a total of $35 \mathrm{~min}$. FT-ICR MS spectra were acquired after $5 \mathrm{~min}$, for a total of $25 \mathrm{~min}$, with similar ion transmission conditions to those used during direct-infusion APLI-FT-ICR MS but without averaging and with a shorter collection time of 2 MWord (1 s transient), resulting in an experimental MS resolving power with AMP at $m / z 400$ of 264000 . 


\section{Data Processing}

FT-ICR MS spectra were externally and internally calibrated using a Tuning Mix standard (Tunemix, G2421A, Agilent Technologies, Santa Clara, CA) ${ }^{53}$ and known PAH series, respectively. The peak lists were generated allowing for a S/N ratio of 6 . For GC-APLIgenerated data, the summed MS of all the scans was used to generate the peak list. The formulas calculations from the exact mass domain were performed using Composer software (Version 1.0.6, Sierra Analytics, CA) with a maximum formula of $\mathrm{C}_{1-100} \mathrm{H}_{1-100} \mathrm{~N}_{0-2} \mathrm{O}_{0-2} \mathrm{~S}_{0-2}$, odd and even electron configurations allowed, and a mass tolerance of $0.5 \mathrm{ppm}$. Two-dimensional GC-FT-ICR MS data were processed by generating the extracted ion chromatography (EIC) chromatograms for each chemical formula, using Data Analysis software (version 4.2SR2, Bruker Daltonics, Inc., Billerica, MA); peak detection (isomer contribution) on the EIC chromatogram was performed using custom MATLAB scripts with a peak criteria of 4 points across the peak and a minimum $20 \%$ intensity after smoothing using the Whittaker method (with $\lambda=6$ ). ${ }^{54}$ The double-bond equivalents (DBEs) versus carbon number and retention time versus carbon number plots were generated using MATLAB software (R2014b, MathWorks, Inc., Natick, MA).

\section{RESULTS AND DISCUSSION}

The analysis of the OSO, PCO, and HSO fossil oils standards using APLI-FT-ICR MS can be characterized by broad distributions in the $\mathrm{m} / z$ 100-900 range centered between $\mathrm{m} / \mathrm{z}$ 400-500 (Figure 1, top black spectra). These broad distributions are in good agreement with previous studies of fossil oils using API sources (e.g., ESI, APCI, APPI, LDI). $3,8,20,21,29,43,55-61$ The broad distributions can be attributed to the large number of compounds, the chemical diversity, and the number of components per heteroatom PAH series commonly encountered in the fossil oils. The sum of all the individual mass spectrum of the GC-APLI-FT-ICR MS analysis (Figure 1, bottom red spectra) shows that, although the MS spectrum does not have the added benefit of multiple coadded transients (i.e., 25 added transients in the case of APLI-FT-ICR MS), the simplified ion population allows for sensitive detection and high mass accuracy using half of the transient time. Closer inspection shows that the GC-APLI-FT-ICR MS spectrum has a high mass cutoff at $\mathrm{m} / z \approx 450$, as a consequence of the volatility range of compounds that are eluted from the GC separation. This mass cutoff results in large differences in the number of assignments when comparing between GC-APLI-FT-ICR MS and APLI-FT-ICR MS: 1734, compared to 6272 for the PCO; 1723, compared to 9188 for the OSO; and 1655, compared to 6216 for the HSO. The total number of unique chemical compounds identified from the combined GC-APLI-FTICR MS and APLI-FT-ICR MS analyses is 6758, 9700, and 7869, for the PCO, OSO, and HSO, respectively, consistent with typically observed numbers in fossil oils reports using APLI-FT-ICR MS. ${ }^{62}$ Taking advantage of the high resolving power and mass accuracy of the FT-ICR MS, chemical signatures were detected for the PCO, OSO, and HSO fossil oils based on the PAH classes and relative abundances (see Figure S-2 in the Supporting Information). That is, inspection of the primary heteroatom PAH series (e.g., HC, N, O, and $S)$ shows differences in the structural composition per class and in the relative compositions of PCO, OSO, and HSO fossil oils (see Figures 2 and 3). For example, the PCO and HSO shows similar $\mathrm{HC}$ and $\mathrm{N}$ composition (typical aromatic limit for the ratio of DBE to carbon 
number ${ }^{63}$ ), in contrast to the $\mathrm{OSO}$ where the most intense series in the $\mathrm{N}$ class corresponds to DBE 3.5 and 4.5 (Figure 2). This OSO signature is indicative of a very intense pyrydinic series ${ }^{64}$ as well as partially aromatic secondary amines series, which has been previously observed in shale oils from the Mahogany zone of the Green River Formation. ${ }^{65,66}$ In all cases, incomplete assignment of the $\mathrm{S}$ class in the higher mass range may be observed, because of insufficient resolving power.

The comparison of the number of compounds detected by GC-APLI-FT-ICR MS and APLIFT-ICR MS shows that GC preseparation enhances the molecular coverage in the $\mathrm{m} / z$ 100450 range (Figure 3). That is, a total of 1928, 3900, and 2087 formulas were identified below $\mathrm{m} / \mathrm{z} 450$ from combined methods for the PCO, OSO, and HSO, respectively. However, 23\%, 13\%, and 27\% (corresponding to 436, 512, and 565 chemical formulas) of the identifications for the PCO, OSO, and HSO, respectively, were detected only when GC preseparation was used. The increase in the number of formula hits can be correlated by class, such as the $\sim 23 \%, \sim 10 \%$, or $25 \%$ increase that is observed for the $\mathrm{HC}, \mathrm{N}$, or O/S classes. This enhancement is notable in the smaller mass and lower DBE species for the HC and $\mathrm{O}$ classes and may be related to ion suppression in the APLI source (see Figure S-3 in the Supporting Information).

The main advantage of APLI sources for the analysis of PAHs is based on the selectivity for ionizing conjugated systems. ${ }^{1,21,25,26,29,45,55,67-70}$ That is, the use of APLI for the analysis of crude oils reduces the presence of common contaminants and interferences (e.g., GC column bleeding, source contamination, solvent impurities, etc.). ${ }^{43,44}$ However, the molecular ionization efficiency during APLI can be limited by (i) matrix effects and (ii) source brightness for the case of complex samples. A comparison between the GC-APLI-FTICR MS and APLI-FT-ICR MS data shows that the reduction in complexity and preconcentration of the GC allows for higher sensitivity (Table 1). That is, lower concentrations can be detected with greater S/N, using GC-APLI-FT-ICR MS, when compared to APLI-FT-ICR MS. The APLI-FT-ICR MS concentration experiment (e.g., 1:5, 1:10, and 1:100 dilutions) suggests that there are no matrix effects (see Figures S-4 and S-5 in the Supporting Information). These experiments showed that the disappearance of small molecules (below $\mathrm{m} / z$ 200) in both sample types was not related to the initial sample concentration. These results suggest that the probability of ionizing by APLI is defined by the number of molecules present in the ionization region, the source fluence, and the photon absorption cross section of the molecule of interest. Other improvements in the detection of the low concentration molecules can be attributed to the reduction of the number of molecules within the ICR cell, thereby increasing the dynamic range. ${ }^{71}$

An analytical benefit of GC-APLI-FT-ICR MS, compared to APLI-FT-ICR MS, is the added potential to separate and identify molecular isomers. That is, ion chromatograms can be generated for targeted PAH compounds with reduced isobaric interferences when using GCAPLI-FT-ICR MS (Figure 4). For example, closer inspection of the 2D GC-MS contour plot shows four molecular formulas and multiple isomers at $\mathrm{m} / z 178$ in the OSO analysis (see Figure 4a and Table S-1 in the Supporting Information). Inspection of the MS projection allows for the assignment of several compounds at the nominal mass level using the high mass accuracy. The most intense peak (labeled "b" in Figure 4a) at $\mathrm{m} / \mathrm{z} 178$ corresponds to 
$\mathrm{C}_{14} \mathrm{H}_{10}$ (error $\left.=-0.21 \mathrm{ppm}\right)$. Inspection of the $\mathrm{C}_{14} \mathrm{H}_{10}(\mathrm{~m} / \mathrm{Z} \pm 0.003)$ chromatogram shows the separation and presence of the molecular isomers phenanthrene and anthracene (previously validated using individual standard analysis). Note that both GC base peak widths obtained during the GC-APLI-FT-ICR MS are similar to those reported using traditional GC-MS separations of OSO SRM. ${ }^{48,72,73}$ That is, the use of APLI-FT-ICR MS did not compromise the GC separation or peak shape.

As the molecular mass increases a larger chemical and structural diversity is observed in the 2D GC-MS plots of fossil oils. For example, closer inspection at $\mathrm{m} / z 256$ of OSO SRM shows multiple interferences that cannot be resolved by GC or MS alone. The MS analysis provided 12 molecular formulas with sub-ppm accuracy (labeled "a"-"l" in Figure 4b; chemical formulas are described in the Table S-1). The high mass separation also permitted the generation of ion chromatograms without interferences per chemical formula (see, for example, $\mathrm{C}_{20} \mathrm{H}_{16}$ and $\mathrm{C}_{17} \mathrm{H}_{20} \mathrm{O}_{2}$ in Figure $4 b$ ). For example, the chromatogram for $\mathrm{C}_{20} \mathrm{H}_{16}$ can be generated without contribution from the other two overlapping $\mathrm{GC}$ signals and $\mathrm{C}_{17} \mathrm{H}_{20} \mathrm{O}_{2}$ from the seven overlapping signals. The GC projections $\mathrm{C}_{20} \mathrm{H}_{16}$ and $\mathrm{C}_{17} \mathrm{H}_{20} \mathrm{O}_{2}$ showed the presence of multiple isomers with $\mathrm{GC}$ peaks of $\sim 10 \mathrm{~s}$ at the base (corresponding to nine FT-ICR MS scans).

An added benefit of the GC-APLI-FT-ICR MS analysis is the possibility to incorporate in the traditional 2D GC-MS plots the DBE information and relative abundances for a better comparison between fossil oils (see Figure 5 for the PCO, OSO, and HSO). That is, GC-MS (with DBE) plots allow for the visualization of signature trends between the fossil oils. For example, if the same GC-MS (with DBE) is plotted as a function of the carbon number per heteroatom class, a better illustration of the structural complexity is obtained within each class. As the retention time increases, an increase in the DBE value is observed per carbon number, in good agreement with previous GC-MS data. ${ }^{48,72,73}$ Inspection of the 2D GC-MS (with DBE) plots (Figure 5) clearly shows the main differences across the fossil oils. For example, differences in the $\mathrm{N}$ series at low DBE between the OSO, and the PCO and HSO, and in the $\mathrm{O}$ series between the PCO, and the OSO and HSO. For the case of targeted analysis, we anticipate that this plot will permit a facile visualization.

The GC-APLI-FT-ICR MS results shown are based on a GC method optimized for broad range elution and sensitivity. Overall, the GC-APLI-FT-ICR MS analytical power is determined by the rate and number of MS spectra that can be collected per GC peak in response to the analytical question see (Figure 6). Traditional GC-MS analysis of PAHs yields broad peaks with good analytical separation (e.g., typically $12 \mathrm{~s}^{72,73}$ and up to $20 \mathrm{~s}^{74}$ ). Assuming that 15 points are acquired across a GC peak, a $12 \mathrm{~s} \mathrm{GC} \mathrm{signal} \mathrm{translates} \mathrm{to} \mathrm{a}$ FTMS transient of $0.8 \mathrm{~s}$, corresponding to $\sim 212000$ mass resolution at $\mathrm{m} / z 400$. In the case of shorter GC signals ( $5 \mathrm{~s}$ ), the GC-APLI-FT-ICR MS coupling can easily provide higher MS resolution (>85 000 at $\mathrm{m} / z 400$ ) than traditional MS analyzers (e.g., quadrupole, ion traps, and time-of-flight (TOF) analyzer). Our results showed that, while the biggest challenge in the GC-FT-ICR MS coupling is the balance between the elution time window of a single compound and the acquisition time for sensitive and accurate mass detection, there are unique advantages in the use of this technique for complex mixtures, such as fossil oils. 


\section{CONCLUSIONS}

The study of fossil oils requires innovative approaches to tackle the chemical diversity and complexity of these samples. In the present study, a GC-APLI source was successfully coupled to a FT-ICR MS for the analysis of fossil oils for the case of organics in shale oil (SRM 1580), petroleum crude oil (SRM 1582), heavy sweet crude oil (SRM 2722) reference standards. Results showed that multiple PAH classes can be easily identified with reduced number of contaminants and interferences when compared with other ionization sources. In particular, the addition of gas chromatography, prior to APLI-FT-ICR MS, increases the ionization efficiency and signal-to-noise ratio of lower abundance fractions. In the mass range covered by the GC analysis $(\mathrm{m} / z$ 100-450), $13 \%-25 \%$ of the chemical identifications are unique to this method. In addition, it was shown that, by adequately balancing the GC separation and the FT-ICR MS acquisition transient, the GC-APLI-FT-ICR MS analysis provides over a 2-fold increase in the number of compounds detected when compared to APLI-FT-ICR MS. That is, the use of GC combined with APLI-FT-ICR MS in the analysis of PAHs results in higher molecular coverage, higher sensitivity, and the possibility to separate and identify molecular isomers from within a crude oil sample.

\section{Supplementary Material}

Refer to Web version on PubMed Central for supplementary material.

\section{ACKNOWLEDGMENTS}

This work was supported by the National Institute of Health (Grant No. R00GM106414) and a FFL Bruker Daltonics, Inc. fellowship. We would like to acknowledge the Advanced Mass Spectrometry Facility of Florida International University for their support.

\section{REFERENCES}

(1). Rodgers RP, McKenna AM. Anal. Chem. 2011; 83:4665-4687. [PubMed: 21528862]

(2). Marshall AG, Rodgers RP. Proc. Natl. Acad. Sci. U. S. A. 2008; 105:18090-18095. [PubMed: 18836082]

(3). Hegazi AH, Andersson JT. Energy Fuels. 2007; 21:3375-3384.

(4). Zadro S, Haken JK, Pinczewski WVJ. Chromatogr. 1985; 323:305-322.

(5). Wang FC-Y, Qian K, Green LA. Anal. Chem. 2005; 77:2777-2785. [PubMed: 15859593]

(6). Robbins WKJ. Chromatogr. Sci. 1998; 36:457.

(7). Kaminski M, Kartanowicz R, Gilgenast E, Namiesnik J. Crit. Rev. Anal. Chem. 2005; 35:193.

(8). Fernandez-Lima FA, Becker C, McKenna AM, Rodgers RP, Marshall AG, Russell DH. Anal. Chem. 2009; 81:9941-9947. [PubMed: 19904990]

(9). Ahmed A, Cho Y, Giles K, Riches E, Lee JW, Kim HI, Choi CH, Kim S. Anal. Chem. 2014; 86:3300-3307. [PubMed: 24592806]

(10). Benigni P, Marin R, Fernandez-Lima F. Int. J. Ion Mobility Spectrom. 2015; 18:151-157.

(11). Lalli PM, Corilo YE, Rowland SM, Marshall AG, Rodgers RP. Energy Fuels. 2015; 29:36263633.

(12). Robinson EW, Garcia DE, Leib RD, Williams ER. Anal. Chem. 2006; 78:2190-2198. [PubMed: 16579597]

(13). Tang X, Bruce JE, Hill HH. Rapid Commun. Mass Spectrom. 2007; 21:1115-1122. [PubMed: 17318922]

(14). Cho Y, Ahmed A, Islam A, Kim S. Mass Spectrom. Rev. 2015; 34:248. [PubMed: 24942384] 
(15). Barrow MP, Peru KM, Headley JV. Anal. Chem. 2014; 86:8281-8288. [PubMed: 25036898]

(16). Heffner C, Silwal I, Peckenham JM, Solouki T. Environ. Sci. Technol. 2007; 41:5419-5425. [PubMed: 17822111]

(17). Luo Z, Heffner C, Solouki TJ. Chromatogr. Sci. 2009; 47:75-82.

(18). Hegazi AH, Fathalla EM, Andersson JT. Chemosphere. 2014; 111:266-271. [PubMed: 24997927]

(19). Zhu X, Shi Q, Zhang Y, Pan N, Xu C, Chung KH, Zhao S. Energy Fuels. 2011; 25:281.

(20). Headley JV, Peru KM, Mohamed MH, Wilson L, McMartin DW, Mapolelo MM, Lobodin VV, Rodgers RP, Marshall AG. Energy Fuels. 2014; 28:1611-1616.

(21). Bae E, Na J-G, Chung SH, Kim HS, Kim S. Energy Fuels. 2010; 24:2563-2569.

(22). Rudzinski WE, Oehlers L, Zhang Y, Najera B. Energy Fuels. 2002; 16:1178-1185.

(23). Hsu CS, Dechert GJ, Robbins WK, Fukuda EK. Energy Fuels. 2000; 14:217-223.

(24). Tose LV, Cardoso FM, Fleming FP, Vicente MA, Silva SR, Aquije GM, Vaz BG, Romão W. Fuel. 2015; 153:346-354.

(25). Stader C, Beer FT, Achten C. Anal. Bioanal. Chem. 2013; 405:7041-7052. [PubMed: 23852149]

(26). Schmitt-Kopplin P, Englmann M, Rossello-Mora R, Schiewek R, Brockmann KJ, Benter T, Schmitz OJ. Anal. Bioanal. Chem. 2008; 391:2803-2809. [PubMed: 18566804]

(27). Schiewek R, Schellenträger M, Mönnikes R, Lorenz M, Giese R, Brockmann K, Gäb S, Benter T, Schmitz O. Anal. Chem. 2007; 79:4135-4140. [PubMed: 17472342]

(28). Streibel T, Zimmermann R. Annu. Rev. Anal. Chem. 2014; 7:361-381.

(29). Cho Y, Jin JM, Witt M, Birdwell JE, Na J-G, Roh N-S, Kim S. Energy Fuels. 2013; 27:18301837.

(30). Terra LA, Filgueiras PR, Tose LV, Romão W, de Castro EV, de Oliveira LM, Dias JC, Vaz BG, Poppi RJ. Fuel. 2015; 160:274-281.

(31). Pereira TMC, Vanini G, Tose LV, Cardoso FMR, Fleming FP, Rosa PTV, Thompson CJ, Castro EVR, Vaz BG, Romão W. Fuel. 2014; 131:49-58.

(32). Rummel JL, McKenna AM, Marshall AG, Eyler JR, Powell DH. Rapid Commun. Mass Spectrom. 2010; 24:784-790. [PubMed: 20187081]

(33). Romão W, Tose LV, Vaz BG, Sama SG, Lobinski R, Giusti P, Carrier H, Bouyssiere B. J. Am. Soc. Mass Spectrom. 2015:1-4.

(34). Wu C, Qian K, Nefliu M, Cooks RG. J. Am. Soc. Mass Spectrom. 2010; 21:261-267. [PubMed: 19914089]

(35). Crawford KE, Campbell JL, Fiddler MN, Duan P, Qian K, Gorbaty ML, Kenttämaa HI. Anal. Chem. 2005; 77:7916-7923. [PubMed: 16351138]

(36). Nyadong L, McKenna AM, Hendrickson CL, Rodgers RP, Marshall AG. Anal. Chem. 2011; 83:1616-1623. [PubMed: 21306132]

(37). Benassi M, Berisha A, Romão W, Babayev E, Römpp A, Spengler B. Rapid Commun. Mass Spectrom. 2013; 27:825-834. [PubMed: 23495029]

(38). Hsu CS, Green M. Rapid Commun. Mass Spectrom. 2001; 15:236-239.

(39). Peterson AC, McAlister GC, Quarmby ST, Griep-Raming J, Coon JJ. Anal. Chem. 2010; 82:8618-8628. [PubMed: 20815337]

(40). Ledford EB, White RL, Ghaderi S, Wilkins CL, Gross ML. Anal. Chem. 1980; 52:2450-2451.

(41). Szulejko J, Solouki T. Anal. Chem. 2002; 74:3434-3442. [PubMed: 12139051]

(42). Smit E, Rüger CP, Sklorz M, De Goede S, Zimmermann R, Rohwer ER. Energy Fuels. 2015; 29:5554.

(43). Lababidi S, Panda SK, Andersson JT, Schrader W. Anal. Chem. 2013; 85:9478-9485. [PubMed: 24063573]

(44). Lababidi S, Schrader W. Rapid Commun. Mass Spectrom. 2014; 28:1345-1352. [PubMed: 24797945]

(45). Zimmermann R, Boesl U, Heger HJ, Rohwer ER, Orthner EK, Schlag EW, Kettrup AJ. J. High Resolut. Chromatogr. 1997; 20:461-470. 
(46). Mühlberger F, Zimmermann R, Kettrup A. Anal. Chem. 2001; 73:3590-3604. [PubMed: 11510823]

(47). Li D-X, Gan L, Bronja A, Schmitz OJ. Anal. Chim. Acta. 2015; 891:43-61. [PubMed: 26388363]

(48). NIST Standard Reference Material 1580. National Institute of Science and Technology (NIST); Gaithersburg, MD: 2012.

(49). NIST Standard Reference Material 1582. National Institute of Science and Technology (NIST); Gaithersburg, MD: 2012.

(50). NIST Standard Reference Material 2722. National Institute of Science and Technology (NIST); Gaithersburg, MD: 2014.

(51). Panda SK, Brockmann K-J, Benter T, Schrader W. Rapid Commun. Mass Spectrom. 2011; 25:2317-2326. [PubMed: 21769956]

(52). Qi Y, Barrow MP, Li H, Meier JE, Van Orden SL, Thompson CJ, O'Connor PB. Anal. Chem. 2012; 84:2923-2929. [PubMed: 22339804]

(53). Cho Y, Qi Y, O'Connor P, Barrow M, Kim S. J. Am. Soc. Mass Spectrom. 2014; 25:154-157. [PubMed: 24096877]

(54). Eilers PHC. Anal. Chem. 2003; 75:3631-3636. [PubMed: 14570219]

(55). Gaspar A, Zellermann E, Lababidi S, Reece J, Schrader W. Anal. Chem. 2012; 84:5257-5267. [PubMed: 22607608]

(56). Purcell JM, Hendrickson CL, Rodgers RP, Marshall AG. Anal. Chem. 2006; 78:5906-5912. [PubMed: 16906739]

(57). Fu J, Kim S, Rodgers RP, Hendrickson CL, Marshall AG, Qian K. Energy Fuels. 2006; 20:661667.

(58). Stanford LA, Rodgers RP, Marshall AG, Czarnecki J, Wu XA, Taylor S. Energy Fuels. 2007; 21:973-981.

(59). Kekäläinen T, Pakarinen JMH, Wickström K, Vainiotalo P. Energy Fuels. 2009; 23:6055-6061.

(60). McKenna AM, Purcell JM, Rodgers RP, Marshall AG. Energy Fuels. 2010; 24:2929-2938.

(61). Hur M, Yeo I, Kim E, No M.-h. Koh J, Cho YJ, Lee JW, Kim S. Energy Fuels. 2010; 24:55245532.

(62). Gaspar A, Zellermann E, Lababidi S, Reece J, Schrader W. Energy Fuels. 2012; 26:3481-3487.

(63). Hsu CS, Lobodin VV, Rodgers RP, McKenna AM, Marshall AG. Energy Fuels. 2011; 25:21742178.

(64). Ingram L, Ellis J, Crisp P, Cook A. Chem. Geol. 1983; 38:185-212.

(65). Li M, Larter SR, Stoddart D, Bjoroey M. Anal. Chem. 1992; 64:1337-1344.

(66). Hillier JL, Fletcher TH, Solum MS, Pugmire RJ. Ind. Eng. Chem. Res. 2013; 52:15522-15532.

(67). Schiewek R, Lorenz M, Giese R, Brockmann K, Benter T, Gäb S, Schmitz OJ. Anal. Bioanal. Chem. 2008; 392:87-96. [PubMed: 18661124]

(68). Rodgers, RP.; Marshall, AG. Asphaltenes, Heavy Oils, and Petroleomics. Berlin, Heidelberg, Germany; Springer: 2007. p. 63-93.

(69). Smith DF, Rahimi P, Teclemariam A, Rodgers RP, Marshall AG. Energy Fuels. 2008; 22:31183125.

(70). Lorenz M, Schiewek R, Brockmann KJ, Schmitz OJ, Gäb S, Benter T. J. Am. Soc. Mass Spectrom. 2008; 19:400-410. [PubMed: 18187335]

(71). Harkewicz R, Belov M, Anderson G, Paša-Tolić L, Masselon C, Prior D, Udseth H, Smith R. J. Am. Soc. Mass Spectrom. 2002; 13:144-154. [PubMed: 11838018]

(72). Wise S, Poster D, Kucklick J, Keller J, VanderPol S, Sander L, Schantz M. Anal. Bioanal. Chem. 2006; 386:1153-1190. [PubMed: 17047949]

(73). Wise SA, Schantz MM, Benner BA Jr. Hays MJ, Schiller SB. Anal. Chem. 1995; 67:1171-1178.

(74). Wise S, Poster D, Leigh S, Rimmer C, Mössner S, Schubert P, Sander L, Schantz M. Anal. Bioanal. Chem. 2010; 398:717-728. [PubMed: 20644914] 
a)

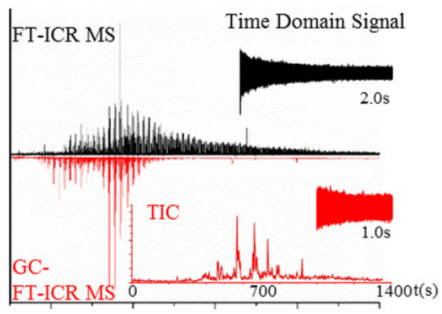

b)

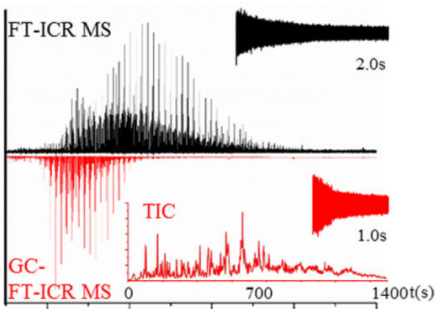

c)

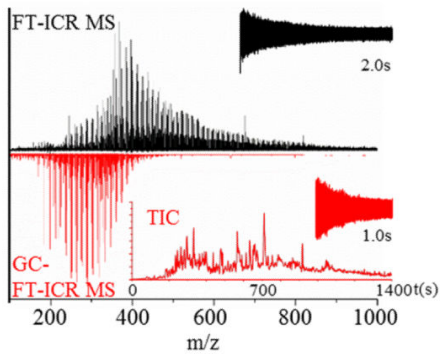

Figure 1.

Typical FT-ICR MS spectra of (a) petroleum crude oil (PCO), (b) organics in shale oil (OSO), and (c) heavy sweet crude oil (HSO) obtained by direct-infusion APLI-FT-ICR MS (top, black spectrum) and GC-APLI-FT-ICR MS (bottom, red spectrum). Also shown is the time domain signal for the direct-infusion analysis (black) and a single scan in the GCFTMS analysis, along with the total ion chromatogram (red). 

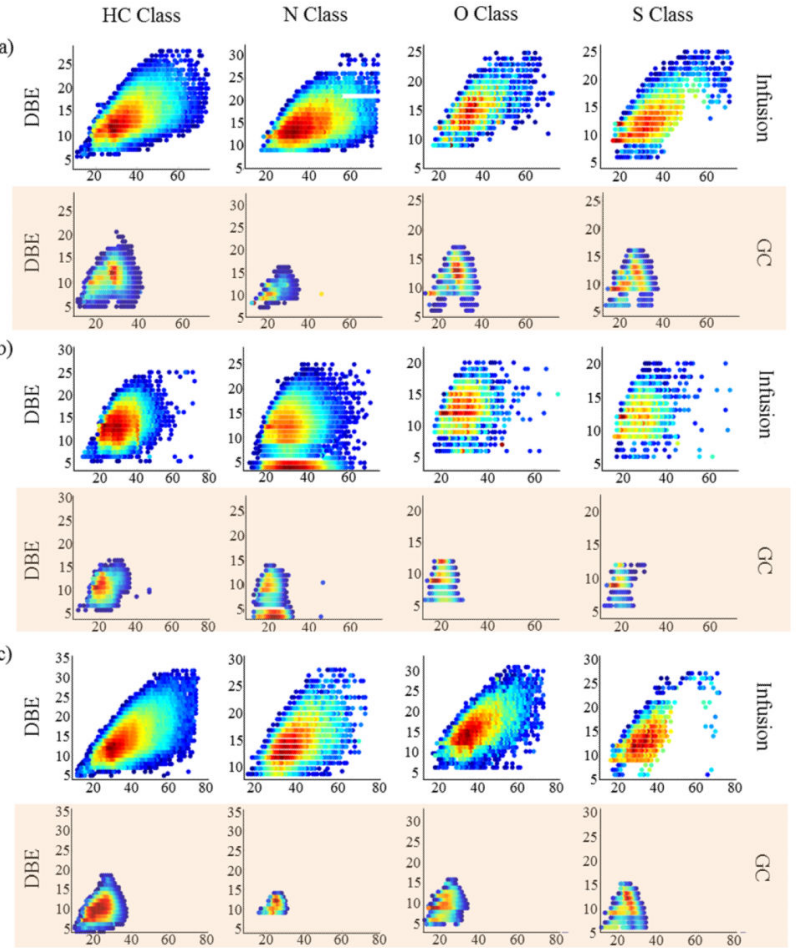

Carbon Number
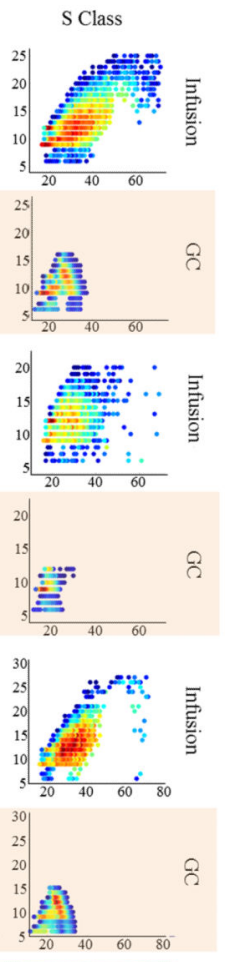

Figure 2.

Double-bond equivalent (DBE) versus carbon number for the HC, N, O and $\mathrm{S}$ classes of (a) petroleum crude oil, (b) organics in shale oil (OSO), and (c) heavy sweet oil (HSO) obtained by direct-infusion APLI-FT-ICR MS (top) and GC-APLI-FT-ICR MS (bottom). 


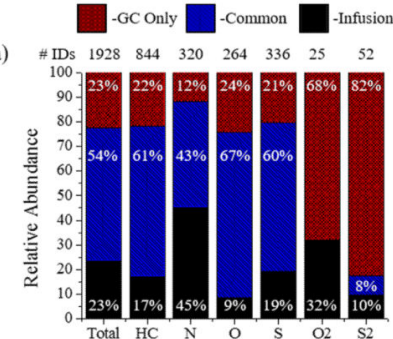

b) \# \# $\begin{array}{lllllllll}3900 & 755 & 1111 & 353 & 316 & 127 & 403 & 557\end{array}$
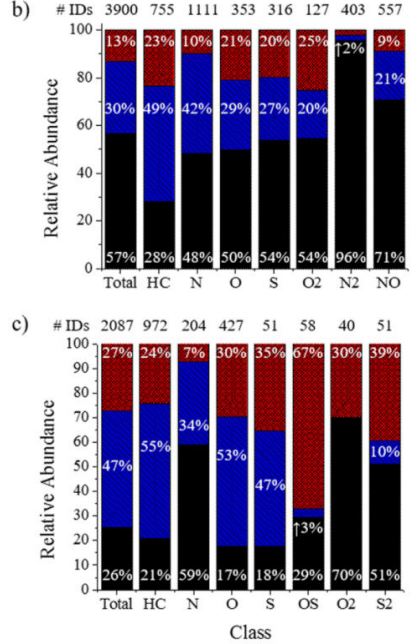

Figure 3.

Percentages of compounds observed only by GC (GC only, red), common between both analysis (blue), and seen by infusion only (black) in the $m / z$ 100-450 range, compared to the total number of identifications, as a function of the heteroatom class in (a) petroleum crude oil (PCO), (b) organics in shale oil (OSO), and (c) heavy sweet oil (HSO). 

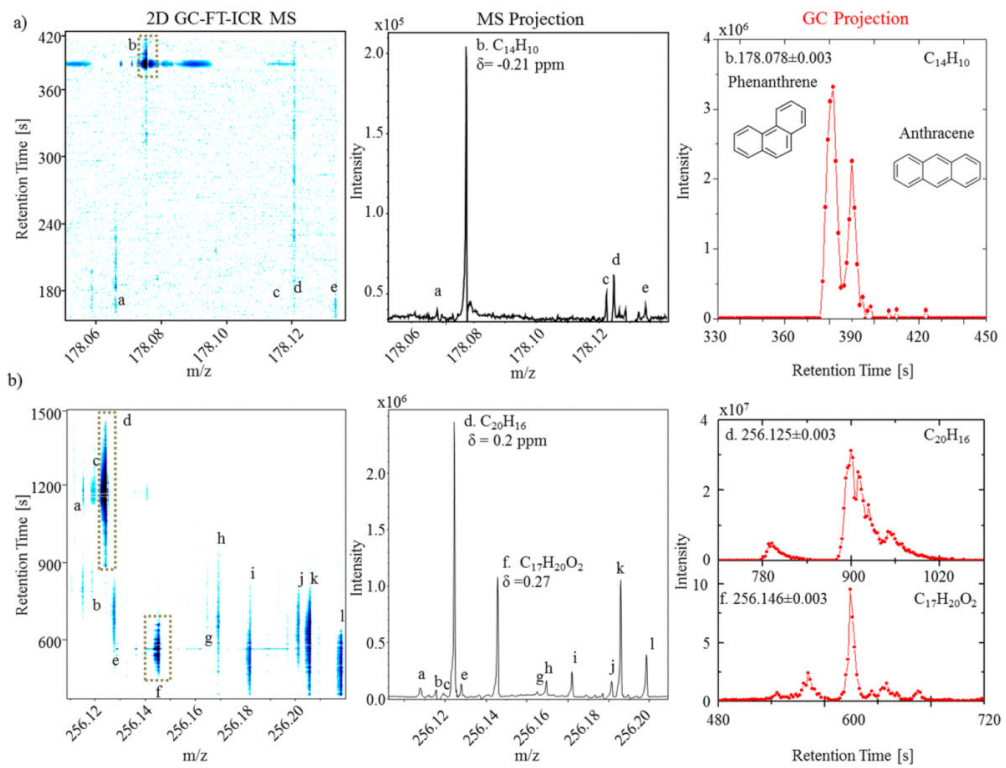

Figure 4.

2D GC-FT-ICR MS contour plots, mass spectrum projections, and selected GC traces for (a) $\mathrm{m} / z=178$ and (b) $\mathrm{m} / z=256$ for the organics in shale oil (OSO). Peak assignments can be found in Table S-1 in the Supporting Information. 


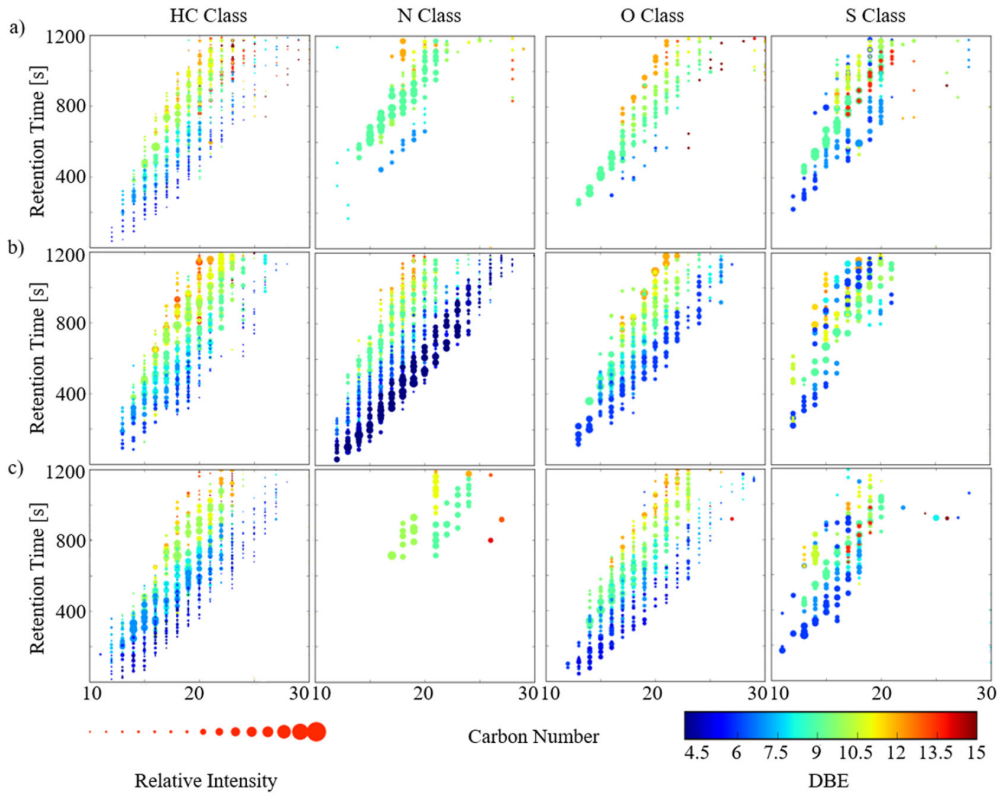

Figure 5.

Two-dimensional (2D) GC-FT-ICR MS contour plots including the double-bond equivalent (DBE, color scale) and relative abundance (symbol size) for the primary heteroatom PAH classes in (a) petroleum crude oil (PCO), (b) organics in shale oil (OSO), and (c) heavy sweet oil (HSO). 


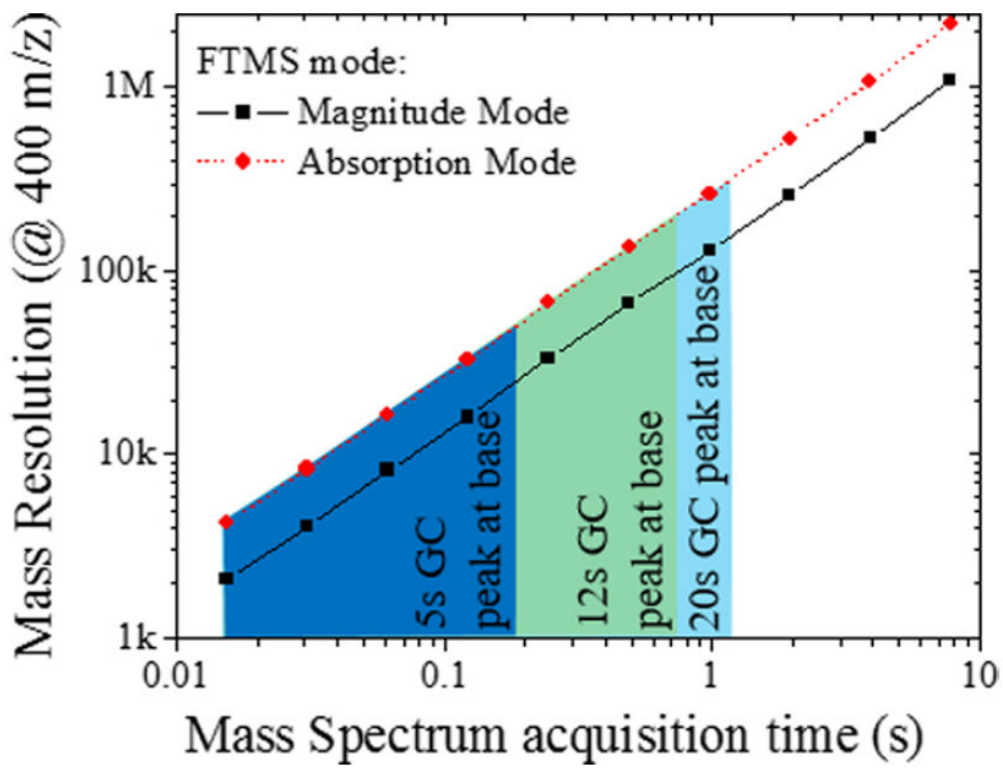

Figure 6.

Typical mass resolution as a function of the transient time in a FT-ICR MS with an infinity cell (7.0 T magnet) using the magnitude and absorption modes. Notice that high mass resolution can be achieved for short GC peaks ( $5 \mathrm{~s})$ and ultrahigh mass resolution can be achieved for GC peaks in the range of 12-20 s, assuming 15 FT-ICR- MS acquisitions per GC peak. 
Table 1

Reported Compounds Observed by APLI-FT-ICR MS and GC-FT-ICR MS in the Organics in Shale Crude Oil and Petroleum Crude Oil Certificates

\begin{tabular}{lclcccccc}
\hline & & & & GC & & \multicolumn{3}{c}{ Infusion } \\
\cline { 7 - 9 } formula & {$[\mathbf{M}]^{+}$} & compound & certificate reference & $\mathbf{1 : 1 0 0}$ & $\mathbf{1 : 1 0 0}$ & $\mathbf{1 : 1 0}$ & $\mathbf{1 : 5}$ \\
\hline $\mathrm{C}_{14} \mathrm{H}_{10}$ & 178.0777 & phenanthrene & SRM 1582 & $\times$ & & & \\
$\mathrm{C}_{16} \mathrm{H}_{10}$ & 202.0777 & fluoranthene & SRM 1580/1582 & $\times$ & & & $\times$ \\
$\mathrm{C}_{16} \mathrm{H}_{10}$ & 202.0777 & pyrene & SRM 1580/1582 & $\times$ & & & $\times$ \\
$\mathrm{C}_{18} \mathrm{H}_{12}$ & 228.0933 & benzanthracene & SRM 1582 & $\times$ & & & $\times$ \\
$\mathrm{C}_{20} \mathrm{H}_{12}$ & 252.0933 & benzopyrene & SRM 1580/1582 & $\times$ & & $\times$ & $\times$ \\
$\mathrm{C}_{20} \mathrm{H}_{12}$ & 252.0933 & perylene & SRM 1580/1582 & $\times$ & & $\times$ & $\times$ \\
$\mathrm{C}_{22} \mathrm{H}_{12}$ & 276.0933 & benzo(ghi)perylene & SRM 1582 & $\times$ & $\times$ & $\times$ & $\times$ \\
$\mathrm{C}_{22} \mathrm{H}_{12}$ & 276.0933 & indeno[1,2,3-cd]pyrene & SRM 1582 & $\times$ & $\times$ & $\times$ & $\times$ \\
$\mathrm{C}_{12} \mathrm{H}_{8} \mathrm{~S}$ & 184.0341 & dibenzothiophene & SRM 1582 & $\times$ & & & \\
\hline
\end{tabular}

